\title{
Development and Validation for RP-HPLC Method of Assay of Omeprazole Capsules Formulation
}

\author{
Mahmoud Mohamed Ali, Eshtiag Abdalla Ibrahim, Mohamed N. Abdalaziz ${ }^{*}$ \\ Department of Chemistry, Faculty of Pure and Applied Science, International University of Africa, Khartoum, Sudan
}

Email address:

mohdnasr19@hotmail.com (M. N. Abdalaziz)

${ }^{*}$ Corresponding author

\section{To cite this article:}

Mahmoud Mohamed Ali, Eshtiag Abdalla Ibrahim, Mohamed N. Abdalaziz. Development and Validation for RP-HPLC Method of Assay of Omeprazole Capsules Formulation. American Journal of Applied and Industrial Chemistry. Vol. 6, No. 1, 2018, pp. 1-6. doi: 10.11648/j.ajche.20180601.11

Received: August 10, 2017; Accepted: September 5, 2017; Published: January 9, 2018

\begin{abstract}
Omeprazole is a potent proton pump inhibitor for the treatment of various acid-related gastrointestinal disorders. simple, selective and rapid reversed phase high performance liquid chromatographic (RP-HPLC) method for the analysis of Omeprazole has been developed and validated. The separation was achieved from HPLC column (ZORBAX, XDB, C-18 $(150 \times 4.6 \mathrm{~mm}, 5$ micron) with a mobile phase consisting of HPLC grade acetonitrile and phosphate buffer solution (pH 7.4) in the ratio of $(60: 40 \mathrm{v} / \mathrm{v})$ at a flow rate of $0.5 \mathrm{ml} / \mathrm{min}$ and runtime $10 \mathrm{~min}$ with $\mathrm{UV}$ detector at $302 \mathrm{~nm}$. The method was specific and it was observed that no interference with diluents. The proposed method was accurate with $100.95 \%$ recovery omeprazole and precise (\% RSD of area of system precision, \% RSD of assay of method precision were found to be $0.14 \%$ and $0.37 \%$ respectively). From the linearity study the correlation coefficient is found to be 0.9988 , which indicated that the method was linear over $25 \%$ to $175 \%$ range. The method was found robust for possible changes. Therefore, this method can be used as a more convenient and efficient option for the analysis of Omeprazole to establish the quality of the drug substance during routine analysis with consistent and reproducible results.
\end{abstract}

Keywords: Omeprazole, HPLC, Validation, Mobile Phase

\section{Introduction}

Omeprazole is a proton pump inhibitor used in the treatment of dyspepsia, peptic ulcer disease (PUD), Gastro esophageal reflux disease (GORD/GERD), and Laryngopharyngeal reflux (LPR) and Zollinger-Ellison syndrome. [1]. Decreasing excess stomach acid can help relieve symptoms such as heartburn, difficulty swallowing, persistent cough, and trouble sleeping. It can also prevent serious acid damage to your digestive system (e.g., ulcers, cancer of the esophagus). This medication may be used in combination with antibiotics to treat certain types of ulcers caused by bacterial infection.

Evidence emerged by the end of the 1970s that the newly discovered proton pump $(\mathrm{H}+/ \mathrm{K}+$-ATPase $)$ in the secretory membrane of the parietal cell was the final step in acid secretion. [2] Literature from an aesthetic screenings led attention to the potential antiviral compound pyridylthioacetamide which after further examination pointed the focus on an anti-secretory compound with unknown mechanisms of action called timoprazole. [3] [4].

Proton pump inhibitors are prodrugs and their actual inhibitory form is somewhat controversial. In acidic solution, the sulfenic acid is isolated before reaction with one or more cysteines accessible from the luminar surface of the enzyme, a tetracyclic sulfenamide. This is a planar molecule thus any enantiomer of a PPI loses stereospecifity upon activation. [5]

Omeprazole is a substituted benzimidazole proton pump inhibitor. It is a racemate and contains a tricoordinated sulfinyl sulfur in a pyramidal structure and therefore can exist in equal amounts of both the (S) - and (R)-enantiomers. In the acidic conditions of the canaliculi of parietal cells, both are converted to achiral products (sulfenicacid and sulfenamideconfigurations) which react with a cysteine group in hydrogen potassium $(\mathrm{H}+/ \mathrm{K}+)$ - ATPase, thereby inhibiting the ability of the parietal cells to produce gastric acid. Omeprazole is chemically designated as 5-Methoxy-2-[(RS)- 
[(4-methoxy-3,5-dimethylpyridin-2-yl) methyl] sulfinyl]-1H benzimidazole. [6] With an empirical formulaC $\mathrm{C}_{17} \mathrm{H}_{19} \mathrm{~N}_{3} \mathrm{O}_{3} \mathrm{~S}$ and its molecular weight is $345.42 \mathrm{~g} / \mathrm{mol}$. [7] [8] the chemical structure of omeprazole is as shown in Figure $1[6]$.<smiles>COc1ccc2[nH]c(S(=O)Cc3ncc(C)c(OC)c3C)nc2c1</smiles>

Figure 1. Chemical structure of omeprazole. [6]

Process for the manufacture of omeprazole or esomeprazole from pyrmethyl alcohol via pyrmethyl chloride and pyrmetazole characterized in that the whole reaction sequence is carried out in a solvent without any isolation or purification of intermediates. Further, the reaction is carried out in a solvent system common for the whole reaction sequence and inert to the reactants formed during the process and used in the process and comprises a water immiscible organic solvent and a specified amount of pharmaceutical ingredient. [9]

Several analytical methods for the determination of omeprazole in pharmaceutical formulations, have been reported in literature. A method for the determination of omeprazole in bulk and capsule dosage form by reverse phase high performance liquid chromatography has been developed. This is a simple, rapid, precise and an accurate method. The method was developed on a Novapak C18, (250x4.6 mm, $5 \mu$ ) column using phosphate buffer ( $\mathrm{pH} 7.4)$ and acetonitrile in the ratio of $60: 40, \mathrm{v} / \mathrm{v}$ as a mobile phase which was pumped at a flow rate of $1.0 \mathrm{ml} / \mathrm{min}$ and detection was done at $302 \mathrm{~nm}$. The retention time of the drug was found to be $7.71 \mathrm{~min}$. The method was validated for accuracy, precision, linearity, specificity, robustness. The linearity was observed in the range of 20-60 ppm. The results of recovery studies indicated that the method was accurate. Hence the developed method was found to be suitable for the estimation of omeprazole in bulk and capsule dosage forms [10] Therefore, the study was aimed to develop a rapid, simple, precise and accurate High performance liquid chromatographic (HPLC) method for the determination of Omeprazole in pharmaceutical formulations (capsules).

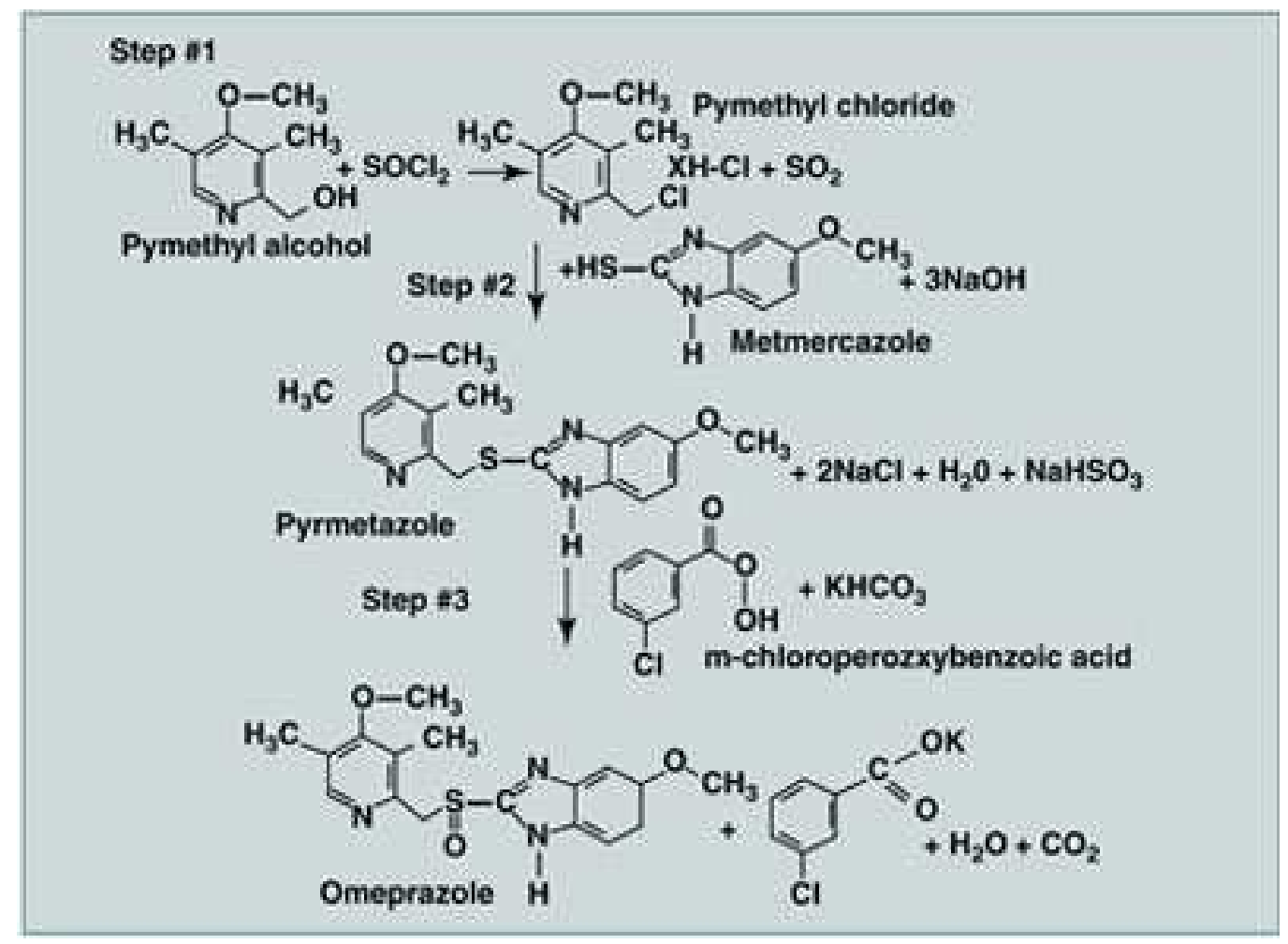

Figure 2. Synthesis of omeprazole. [9]

\section{Experimental}

Instruments and reagents

HPLC Model (Younglin 9100), Make (Younglin), Auto sampler (YL9150), Column compartment (YL9131), UV/VIS Detector (YL9120), Vacuum Degasser (YL9101). Acetonitrile, Di potassium hydrogen phosphate, Methanol,
Omeprazole USP Working standard, Omeprazole Capsules $20 \mathrm{mg}$, Potassium dihydrogen orthophosphate, Sodium hydroxide.

Chromatographic conditions

Column (ZORBAX XDB-C-18,150 x $4.6 \mathrm{~mm}$ ), $5 \mu \mathrm{m}$ or Equivalent, Flow rate $(0.5 \mathrm{ml} / \mathrm{min})$ Column temperature

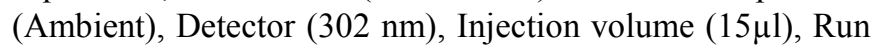
time (10minutes). 


\section{Preparation of buffer solution}

About 272 mg of Potassium dihydrogenorthophosphateand $525 \mathrm{mg}$ of di potassium hydrogen phosphate were weighted accuratelyand transferred to a $1000 \mathrm{ml}$ volumetric flask, sufficient water was addedto dissolvingand makeup with water up to the mark, the $\mathrm{pH}$ was adjusted to $7.40 \pm 0.05$ with Sodium hydroxide and the buffer was filtered through $0.45 \mu$ membrane filter.

Mobile phase

A mixture of $600 \mathrm{ml}$ of buffer and $400 \mathrm{ml}$ of Acetonitrile were prepared.

Preparation of Standard Solution:

$20 \mathrm{mg}$ of Omeprazole WRS were weighted accurately in beaker, dissolved in $50 \mathrm{ml}$ of volumetric flask andwas diluted to volume with Methanol. $1 \mathrm{ml}$ of this solution was pipetted out to $10 \mathrm{ml}$ volumetric flask and was diluted to the volume with methanol and filtered with whattman paper0.45micron membrane filter.

Preparation of Sample Solution:

The contents of 10 Capsules of Omeprazole were weighted and grinded by mortar and pestle and mixed to uniform powder, $20 \mathrm{mg}$ of Omeprazole were weighted accurately in plate beaker then dissolved and transferred to $50 \mathrm{ml}$ volumetric flask, and sonicated for 20 minutes, and was diluted with the same solvent to the mark and filtered by whattman paper. $1 \mathrm{ml}$ of this solution was pipetted to $10 \mathrm{ml}$ of volumetric flask and diluted volume with Methanol and was injected in HPLC.

Evaluation of System Suitability Solution:

$15 \mu \mathrm{l}$ of standard solution were injected, in six replicate injections, into the chromatograph and the chromatograms was recorded, the column efficiency was determined from the Omeprazole peak is not less than 2500 theoretical plates. The tailing factor for Omeprazole peak is not more than 2.0. RSD for 6 replicate injections is not more than $2.0 \%$, and $15 \mu \mathrm{l}$ of the sample solution were injected, in duplicate into the chromatographs were recorded and were measured the chromatogram speaks areas.

$\frac{\text { sample area }}{\text { standard area }} \times \frac{\text { standard dilution }}{\text { sample dilution }} x \frac{\text { standard Purity }}{100} \times$ Average weight $=m g /$ Capsule

\section{Acceptance Criteria}

Not less than $19.0 \mathrm{mg} / \mathrm{cap}(95 \%)$ and not more than $21.0 \mathrm{mg} / \mathrm{Cap}(105 \%)$.

\section{Method Validation}

The Proposed test method was validated to include requirements of international conference on Harmonization (ICH) guidelines, in terms of specificity, linearity, precision (method precision) accuracy, range and robustness.

\section{Specificity}

Specificity is the ability to assess unequivocally the analyte in the presence of components which may be expected to be present. This definition has following implication for assay test. Table 1, 2, 3 .

Standard Preparation

$21.00 \mathrm{mg}$ of Omeprazole working standard were weighted accurately and transferred to a $50 \mathrm{ml}$ volumetric flask and completed to mark with methanol. Immediately prior to chromatography, $1.0 \mathrm{ml}$ of standard stock solution was transferred to $10 \mathrm{ml}$ volumetric flask and diluted to the volume with methanol.

Sample Preparation 1\&2

$(279.30,280.80) \mathrm{mg}$ of "omeprazole pellets" sample were weighted accurately and transferred into $50 \mathrm{ml}$ volumetric flask and dissolved in methanol, diluted to the volume with methanol, filter with 0.45 micron whattman filter paper. Immediately prior to chromatography, $1.0 \mathrm{ml}$ of this solution was transferred to $10 \mathrm{ml}$ volumetric flask and diluted to the volume with methanol.

\section{System precision}

System suitability and standard solution were prepared and injected as per the method.

Method precision

The assay of "Omeprazole for capsule" sample was determined in six preparations as per the method of analysis.

Sample Preparation from 1 to 6

$(280.1,280.5,280.2,280.7,280.9,280.1) \mathrm{mg}$ of "omeprazole pellets" sample were weighted accurately and transferred to $50 \mathrm{ml}$ volumetric flask and dissolved in methanol, diluted to the volume with methanol, filtered with 0.45 micron whattman filter paper. Immediately prior to chromatography, $1.0 \mathrm{ml}$ of this solution was transferred to $10 \mathrm{ml}$ volumetric flask and diluted to the volume with methanol.

\section{Linearity}

Linearity was assessed using seven preparations of Omeprazole working standard of concentration ranging from $0.01 \mathrm{mg} / \mathrm{ml}$ to $0.07 \mathrm{mg} / \mathrm{ml}$ i.e. $25 \%, 50 \%, 75 \%, 100 \%$, $125 \%, 150 \%$ and $175 \%$ of test concentration.

\section{Accuracy}

Accuracy has been established by preparing the sample at three concentrations levels $(80 \%, 100 \%$ \& 120\%) and calculate the \% RSD for the obtained assay values.

Robustness

The robustness of analytical procedure is a measure of its capacity to remain unaffected by small, but deliberate variations in method parameters and provides an indication of its reliability during normal usage.

The System suitability of "Omeprazole" was determined as per the method of analysis but with deliberate variations in flow rate by $\pm 20 \%$.

\section{Results and Discussion}

\section{Specificity}

Specificity of an analytical method is its ability to assess unequivocally the analyte in the presence of components that may be expected to be present. Lack of specificity of an individual analytical procedure may be compensated by other supporting analytical procedures. From the specificity study, it was observed that the chromatogram for omeprazole sample with omeprazole standard show positive response and blank (diluents) has no response. Results of test solution 
showed that there is no interference of the excipients when compared with the working standard solution. Thus, the method was said to be specific. Table (1) and (2).

Table 1. Specificity of standard Area.

\begin{tabular}{lll}
\hline S.NO & RETEINION TIME & STANDARD AREA \\
\hline 1 & 5.477 & 3109.500 \\
2 & 5.483 & 3102.639 \\
3 & 5.523 & 3109.191 \\
4 & 5.483 & 3109.662 \\
5 & 5.490 & 3116.378 \\
6 & 5.507 & 3108.616 \\
AVERAGE & 5.49 & 3109.33 \\
STDEV & 0.02 & 4.36 \\
RSD & 0.32 & 0.14 \\
\hline
\end{tabular}

Table 2. Specificity of sample Area.

\begin{tabular}{lll}
\hline S.NO & RETEINION TIME & SAMPLE AREA \\
\hline 1 & 5.497 & 3363.459 \\
2 & 5.540 & 3393.523 \\
AVERAGE & 5.52 & 3378.49 \\
STDEV & 0.03 & 21.26 \\
RSD & 0.6 & 0.6 \\
\hline
\end{tabular}

\section{Precision}

System precision

System suitability and standard solution were prepared and injected as per the method. The \% RSD calculated for the area responses of Omeprazole peak are summarized in Table (1).

\section{Method precision}

The assay of "Omeprazole for capsule" sample was determined in six preparations as per the method of analysis. The \% RSD for the calculated values of assay is tabulated in Table (3).
Table 3. Method Precision of Assay \%.

\begin{tabular}{lll}
\hline Sr.No & $\begin{array}{l}\text { Area response of omeprazole } \\
\text { working standard(System } \\
\text { Precision) }\end{array}$ & Assay \% \\
\hline 1 & 3109.500 & 100.1 \\
2 & 3102.639 & 100.0 \\
3 & 3109.191 & 100.1 \\
4 & 3109.662 & 99.1 \\
5 & 3116.378 & 99.6 \\
6 & 3108.616 & 99.9 \\
AVERAGE & 3109.33 & 99.80 \\
STDEV & 4.36 & 0.37 \\
\%RSD & 0.14 & 0.37 \\
\hline
\end{tabular}

Linearity and Range

To demonstrate the linearity of detector response for Omeprazole assay method, seven standard solutions with concentration ranging from $25 \%$ to $175 \%$ of omeprazole were prepared to cover the concentration of omeprazole from $10 \mathrm{ppm}$ to $70 \mathrm{ppm}$. The chromatograms were recorded for these solutions under optimal conditions and the peak areas were measured. A graph was plotted between concentration ( $\mu \mathrm{g} \mathrm{mL}^{-1}$ ) and average peak area (absorbing units). The data was used for statistical analysis using a linear regression model. The statistical parameters of linear curve, slope, intercept and coefficient of determination values were calculated and shown in Figure 3.

The linearity curve was established by plotting the values of concentration $\left(\mu \mathrm{gmL}^{-1}\right)$ on $\mathrm{X}$-axis and obtained areas from chromatographic system (absorbing units) on $\mathrm{Y}$-axis as determined from linearity test table (4). The obtained coefficient of determination $\left(r^{2}\right.$ is 0.9988$)$ shows that the calibration curve is very much linear in the concentration range mentioned.

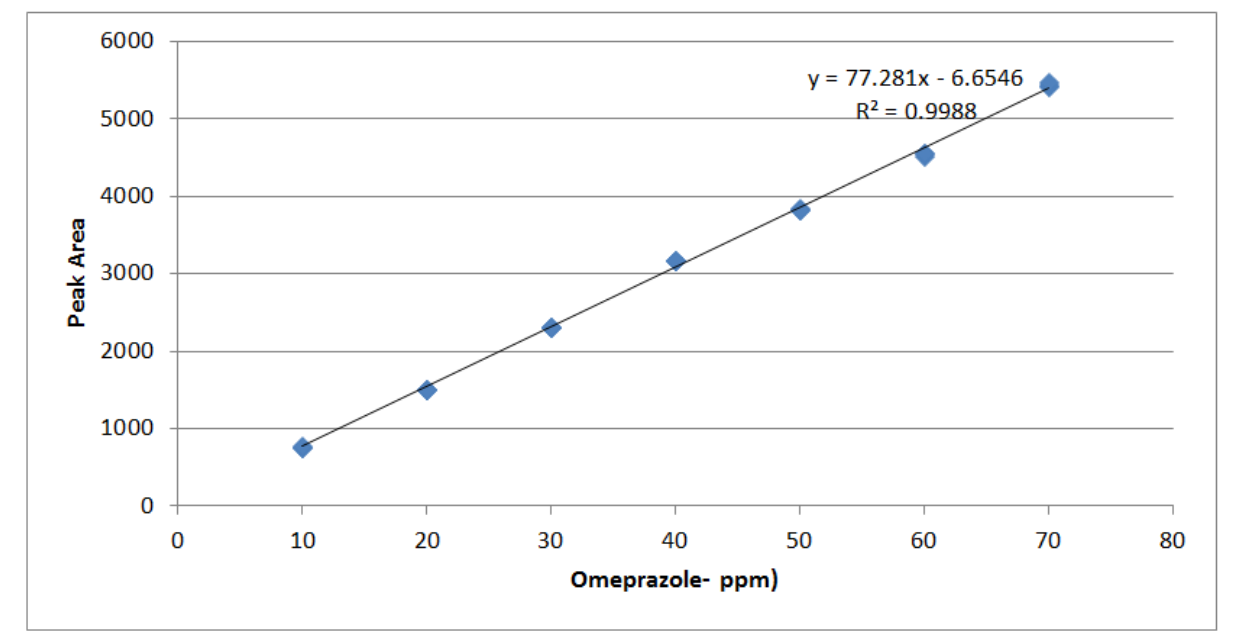

Figure 3. Linearity of Omeprazole Capsule.

\section{Range}

To demonstrate the range of the analytical method, data from seven values of lower and higher concentration solutions of accuracy preparation was considered. The obtained mean recovery at lowest level and highest level was found between
$99.0 \%$ and $102.0 \%$ with the coefficient of determination $\left(\mathrm{r}^{2}\right)$ above 0.995 and relative standard deviation for six preparations was found below $2.0 \%$ which shows that the analytical method is more accurate and precise throughout its range of $10 \mu \mathrm{g} \mathrm{mL}^{-1}$ to $70 \mu \mathrm{g} \mathrm{mL}^{-1}$ of omeprazole. Table (4). 
Table 4. Summary Report of Linearity and Range.

\begin{tabular}{|c|c|c|c|}
\hline S. No & Procedure & Results & Acceptance criteria \\
\hline 1 & Inject blank preparation & There is no interference due to blank & No interfering peaks shall be observed \\
\hline 2 & System suitability & $\begin{array}{l}\text { The tailing factor for analyte peak obtained from } \\
\text { the standard preparation is found to be } 1.024 \\
\text { The \% RSD obtained the six replicate injections } \\
\text { of standard preparation is found to be } 0.19\end{array}$ & $\begin{array}{l}\text { The tailing factor for the analyte peak obtained from } \\
\text { the standard preparation should be not more than } 2.0 \\
\text { The \% RSD obtained for the six replicate injections } \\
\text { of standard preparation should be not more than } 2.0\end{array}$ \\
\hline 3 & $\begin{array}{l}\text { Inject standard solution of } 25,50 \text {, } \\
75,100,125,150 \text { and } 175 \% \text { of test } \\
\text { concentrations, respectively, in } \\
\text { linearly }\end{array}$ & $\begin{array}{l}\text { The Correlation coefficient for the obtained } \\
\text { calculated values was found to be } 0.9988\end{array}$ & $\begin{array}{l}\text { Plot a graph between concentration and average area, } \\
\text { determine the correlation coefficient it shall not be } \\
\text { less than } 0.995\end{array}$ \\
\hline
\end{tabular}

\section{Accuracy}

To ascertain the accuracy of the proposed methods, recovery studies were carried out by standard addition method at three different levels $(80 \%, 100 \%$ \& 120\%). Average percent recovery for Omeprazole was found to be $100.95 \%$ respectively Table (5).

Table 5. Accuracy of Recovery Results.

\begin{tabular}{|c|c|c|c|c|}
\hline S.No & Level \% & $\begin{array}{l}\text { Amount added } \\
\text { in } \mathrm{mg}\end{array}$ & $\begin{array}{l}\text { Amount found } \\
\text { in } \mathrm{mg}\end{array}$ & $\begin{array}{l}\text { Recovery } \\
(\%)\end{array}$ \\
\hline & & & 16.29 & 101.85 \\
\hline \multirow[t]{3}{*}{1} & 80 & 16 & 16.29 & 101.85 \\
\hline & & & 16.28 & 101.78 \\
\hline & & & 20.09 & 100.43 \\
\hline \multirow[t]{3}{*}{2} & 100 & 20 & 20.11 & 100.56 \\
\hline & & & 20.11 & 100.54 \\
\hline & & & 24.11 & 100.45 \\
\hline \multirow[t]{5}{*}{3} & 120 & 24 & 24.12 & 100.50 \\
\hline & & & 24.13 & 100.56 \\
\hline & & AVERAGE & & 100.95 \\
\hline & & STDEVA & & 0.66 \\
\hline & & RSD & & 0.66 \\
\hline
\end{tabular}

\section{Robustness}

The robustness of the proposed method was demonstrated by the results obtained in the study of system suitability parameter by injecting the standard preparation with variable flow rates $\left(0.4,0.5\right.$ and $0.6 \mathrm{ml}$ minute $\left.^{-1}\right)$ The overall \% RSD of less than 1.0for System suitability of Omeprazole standard values demonstrates that the method employed for determination of assay of "Omeprazole for capsule" is robust to variation in mobile phase flow rate.

The overall \% RSD of less than 1.0 for System suitability of Omeprazole standard values demonstrates that the method employed for determination of assay of "Omeprazole for capsule" is robust to variation in mobile phase flow rate. Table (6), (7) and (8).
Table 6. Robustness of flow rate: $0.4 \mathrm{ml} / \mathrm{min}$.

\begin{tabular}{lll}
\hline Flow Rate:0.4ml/min & & \\
\hline S. No & RT & AREA \\
\hline Std-01 & 6.967 & 3812.236 \\
Std-02 & 6.883 & 3811.866 \\
Std-03 & 6.967 & 3827.684 \\
Std-04 & 6.923 & 3811.267 \\
Std-05 & 6.947 & 3806.347 \\
Std-06 & 6.973 & 3800.76 \\
Average & 6.94 & 3811.69 \\
STDEV & 0.03 & 8.99 \\
RSD & 0.50 & 0.24 \\
\hline
\end{tabular}

Table 7. Robustness of flow rate: $0.5 \mathrm{ml} / \mathrm{min}$.

\begin{tabular}{lll}
\hline Flow Rate:0.5ml/min & & \\
\hline S. No & RT & AREA \\
\hline Std-01 & 5.513 & 3019.352 \\
Std-02 & 5.517 & 3083.995 \\
Std-03 & 5.543 & 3085.907 \\
Std-04 & 5.53 & 3078.311 \\
Std-05 & 5.507 & 3076.857 \\
Std-06 & 5.513 & 3079.325 \\
Average & 5.52 & 3070.62 \\
STDEV & 0.01 & 25.36 \\
RSD & 0.24 & 0.83 \\
\hline
\end{tabular}

Table 8. Robustness of flow rate: $0.6 \mathrm{ml} / \mathrm{min}$.

\begin{tabular}{lll}
\hline Flow Rate:0.6ml/min & & \\
\hline S. No & RT & AREA \\
\hline Std-01 & 4.59 & 2548.237 \\
Std-02 & 4.573 & 2544.664 \\
Std-03 & 4.55 & 2554.225 \\
Std-04 & 4.577 & 2543.491 \\
Std-05 & 4.567 & 2540.216 \\
Std-06 & 4.563 & 2539.441 \\
Average & 4.57 & 2545.05 \\
STDEV & 0.01 & 5.51 \\
RSD & 0.30 & 0.22 \\
\hline
\end{tabular}

Table 9. Summary of the Report.

\begin{tabular}{lllll}
\hline Sl. No & Validation Parameter & Acceptance Criteria & Validation Results & Remarks \\
\hline 1 & Specificity & Free from Matrix or Spectral & As the HPLC Chart shows distinct peak with respect to each & Complies \\
2 & Repeatability & Interference & 0.37 & Complies \\
3 & Recovery & $80 \%-120 \%$ & $100.95 \%$ & Complies \\
4 & LOD & NOT APPLICABE & $2.44 \mathrm{mg} / \mathrm{kg}$ & NA \\
5 & LOQ & NOT APPLICABE & $7.33 \mathrm{mg} / \mathrm{kg}$ & NA \\
\hline
\end{tabular}




\section{Conclusion and Recommendations}

The test method is validated for specificity, precision, linearity, range and robustness. The result obtained meets the acceptance criteria and determination of assay of "Omeprazole for capsule". The results of recovery studies indicated that the method was accurate. Hence the developed method was found to be suitable for the estimation of omeprazole in capsule dosage forms.

\section{References}

[1] Indian Pharmacopoeia, Vol. II, Govt. of India, Ministry of Health and Family Welfare. New Delhi; Published by The Controller of Publications; 1996.

[2] Forte, JG; Lee, (1977). HC "Gastric adenosine triphosphates: A review of their possible role in $\mathrm{HCl}$ secretion". Gastroenterology 73 (4 Pt 2): 921-6. PMID20386.

[3] Snaeder, W, (1996). Drug prototypes and their exploitation. Wiley. pp. 414-5.
[4] Hemenway, Jeffrey Nm, (2007). "Case Study: Omeprazole (Prilosec $\mathbb{R})$ ). Prodrugs. Biotechnology: Pharmaceutical Aspects. pp. 1313-21. doi:10.1007/978-0-387-49785-3_49. ISBN978-0-387-49782-2.

[5] Shin, Jai Moo; Munson, Keith; Vagin, Olga; Sachs, George, (2008). "The gastric HK-ATPase: Structure, function, and inhibition". Pflügers Archiv - European Journal of Physiology 457 (3): 609-22. doi:10.1007/s00424-008-0495-4 PMC3079481. PMID18536934.

[6] British Pharmacopoeia, (2013). Vol.1, the British Pharmacopoeia Commission, London.

[7] United States Pharmacopia, 30-NF-25 31 (4) 1100.

[8] Sweetman SC. Martindale, (2002) - The Complete Drug Reference, (3 rd Edition) Pharmaceutical Press, London, 1241-1243.

[9] Girish Malhotra, (2010). "Chemical Process Simplification: Improving Productivity and Sustainability" ch 5 to be published John Wiley \& Sons.

[10] Kalakonda Sri Nataraj, Mohammad Badrud Duza, Kalyani Pragallapati, Dussa Kiran Kumar, (2012). International Current Pharmaceutical Journal, 1(11): 366-369. 